\title{
Brief communication: Thinning of debris-covered and debris-free glaciers in a warming climate
}

\author{
Argha Banerjee \\ Earth and Climate Science, Indian Institute of Science Education and Research, Pune, India \\ Correspondence to: Argha Banerjee (argha@iiserpune.ac.in)
}

Received: 16 May 2016 - Published in The Cryosphere Discuss.: 15 June 2016

Revised: 20 December 2016 - Accepted: 25 December 2016 - Published: 18 January 2017

\begin{abstract}
Recent geodetic mass-balance measurements reveal similar thinning rates on glaciers with or without debris cover in the Himalaya-Karakoram region. This comes as a surprise as a thick debris cover reduces the surface melting significantly due to its insulating effects. Here we present arguments, supported by results from numerical flowline model simulations of idealised glaciers, that a competition between the changes in the surface mass-balance forcing and that of the emergence/submergence velocities can lead to similar thinning rates on these two types of glaciers. As the climate starts warming, the thinning rate on a debris-covered glacier is initially smaller than that on a similar debris-free glacier. Subsequently, the rate on the debris-covered glacier becomes comparable to and then larger than that on the debris-free one. The time evolution of glacier-averaged thinning rates after an initial warming is strongly controlled by the time variation of the corresponding emergence velocity profile.
\end{abstract}

\section{Introduction}

A knowledge gap related to debris-covered glacier dynamics affects our understanding of the past and future of Himalayan glaciers in a changing climate (Scherler et al., 2011). The supraglacial debris cover present over the ablation zone of a glacier induces qualitative changes in its dynamic response (Naito et al., 2000; Vacco et al., 2010; Benn et al., 2012; Banerjee and Shankar, 2013; Anderson and Anderson, 2015) due to a suppressed melt rate under a thick debris layer (Nakawo and Young, 1982; Mattson et al., 1993), whereas a thin debris cover is expected to accelerate melt due to its low albedo. While responding to a warming climate, debris-covered glaciers exhibit a larger climate sensitivity, a longer response time (Banerjee and Shankar, 2013), a decoupling of volume and length changes and the formation of a slow-flowing stagnant downwasting tongue (Scherler et al., 2011; Banerjee and Shankar, 2013). Despite several efforts to model and understand the dynamics of debris-covered glaciers with various degrees of sophistication (Naito et al., 2000; Vacco et al., 2010; Banerjee and Shankar, 2013; Anderson and Anderson, 2015; Rowan et al., 2015), challenges still remain. This task is made more difficult by our limited understanding of the time evolution of the debris extent (Anderson and Anderson, 2015), the variability of debris thickness, and common occurrences of highly dynamic supraglacial ponds and ice cliffs that cause intense localised melting (Sakai et al., 2000; Miles et al., 2015; Steiner et al., 2015).

A curious fact that has emerged from large-scale remotesensing measurements of glaciers in the Himalayas and Karakoram during the first decade of the 21 st century is a similar magnitude of thinning of glacial ice irrespective of the presence of supraglacial debris cover (Kääb et al., 2012; Gardelle et al., 2012; Nuimura et al., 2012; Gardelle et al., 2013) and this may seem counter-intuitive. A thick debris cover, due to its insulating properties, significantly inhibits the melting of the underlying ice - so much so that in the debris-covered part of the glacier, the specific melt rate does not increase with decreasing elevation. Rather, it saturates to some lower bound or even decreases downglacier (Banerjee and Azam, 2016). On the other hand, on a debris-free glacier the melt rate typically increases monotonically as elevation decreases. Why then should both glacier types experience similar rates of thinning as climate warms up? 
Heuristic arguments were offered by various authors to reconcile with this apparent paradox. Kääb et al. (2012) suggested that the insulating effect of the debris cover might be compensated for at the scale of the whole ablation zone due to an enhanced melting from the thermokarst processes, namely supraglacial ponds and ice cliffs that are often present on the debris-covered glaciers. These features, due to an associated discontinuous debris cover, experience large localised melting. Given that these features typically contribute $\sim 10-20 \%$ of the total melt (Sakai et al., 2000; Reid and Brock, 2014), it is unlikely that they can lower the glacierwide mean melt rate on debris-covered glaciers sufficiently so that it matches that on the debris-free glaciers. Field measurements by Vincent et al. (2016) seem to confirm this. It was also conjectured that a reduction in ice flux from upstream areas to the stagnant tongue may be behind the largerthan-expected thinning of debris-covered glacial ice (Kääb et al., 2012; Gardelle et al., 2012). Nuimura et al. (2012) too pointed out the possible role of reduced flux into the lowslope slow-moving stagnant tongues of large debris-covered glaciers. However, a quantification of this flux effect is missing as of yet.

On the other hand, Banerjee and Shankar (2013) showed that a reduced melt rate on a debris-covered glacier does not affect the volume response of the glacier qualitatively, in stark contrast with its drastic effect on the length response of the glacier. However, their model results (Fig. 3d of Banerjee and Shankar, 2013) show a relatively larger thinning rate on the debris-free glaciers in response to a rapid warming. Also, it was reported that in the Pamir-Karakoram-Himalayas, depending on the region chosen, geodetic measurement yielded decadal thinning rates of debris-covered ice that were either larger or smaller than, or similar to that of debris-free ice (Gardelle et al., 2013). The present scenario is summed up neatly by Vincent et al. (2016), "This question of areaaveraged melting rates over debris-covered or clean glacier ablation areas remains unanswered".

In this contribution, we analyse the rate of thinning on debris-covered and debris-free glaciers in a warming climate using a one-dimensional flowline model of idealised glaciers (Banerjee and Shankar, 2013; Banerjee and Azam, 2016). We conduct simple numerical experiments to investigate the role of the magnitude of warming rate, the ice dynamics (i.e. the changes in the flux-gradient profiles or equivalently that in emergence/submergence velocities), and that of the surface mass-balance forcing in controlling the thinning rates on these two glacier types.

\section{Glacier response to instantaneous warming}

An easy-to-analyse piece of this problem is the behaviour of a steady-state debris-covered or debris-free glacier immediately after an instantaneous rise of temperature (or equivalently that of the equilibrium line altitude, ELA). In a steady state, the ice-thickness profile remains constant due to a stable balance between the surface ablation (accumulation) rate and the emergence (submergence) velocities. Dictated by mass conservation of incompressible ice, the emergence or submergence rate equals the negative gradient of the flux, $F(x)$. After an instantaneous change in ELA, the surface mass-balance values change, but the viscous ice flow takes a characteristic longer time to relax. Therefore, the local thinning rate is initially just the difference in specific mass balance, $B(x)$, before and after the change in temperature. However this is valid only over a timescale that is short compared to the flow relaxation time.

Let us consider two idealised model glaciers. Glacier A does not have any debris cover and has a linear mass-balance profile. Glacier B has a supraglacial debris cover on its lower ablation zone where the ablation rate saturates to a value of $-2 \mathrm{~m} \mathrm{yr}^{-1}$ (Fig. 1b). This idealised mass-balance profile for the debris-covered glacier is motivated by data from a Himalayan glacier (Banerjee and Azam, 2016). Similar simplified mass-balance profiles have been used to analyse the response of the debris-covered Himalayan glaciers (Banerjee and Shankar, 2013; Banerjee and Azam, 2016). In a real glacier, the possible variability of debris thickness and ephemeral thermokarst features (ponds and ice cliffs) cause significant spatial variation of the melt rate in the debriscovered parts of the glacier. However, a relatively fast advection of these surface features would imply that a longterm mean melt rate at a specific location is a well-defined quantity. This justifies the simplified mass-balance profile employed here. Further, the observed thinning rate values in the Himalayas are obtained for a large set of glaciers so that the possible effects of specific details of mass-balance profile of individual glaciers would be averaged out.

In Fig. 1a, b we show mass-balance profiles for the idealised model glaciers before and after an instantaneous rise of ELA, $\Delta E=50 \mathrm{~m}$. It is assumed here that the mass-balance shape remains the same and changes only by a shift of ELA. In practice the debris layer may thicken and the debriscovered area may grow in a warming climate, affecting the shape of the melt rate profile. However, it is known that above a debris thickness of $\sim 10 \mathrm{~cm}$, the decrease in melt rate with a thickening debris layer is small (Juen et al., 2014). Therefore such changes can safely be neglected as a first approximation. The possible changes in supraglacial ponds/ice cliffs are neglected at this level of approximation due to a relatively smaller contribution of these features to the total melt, as discussed before. This assumption of an invariant shape allows for the possible increase in debris extent with warming as the upper boundary of the region with saturated melt rate moves up with the ELA. Overall these simplifications allow us to focus on the role of ice flow dynamics in controlling the downwasting of glaciers in a warming climate.

As is clear from Fig. 1a, glacier A responds initially with a uniform glacier-wide thinning rate, $\left\langle\frac{\mathrm{d} h}{\mathrm{~d} t}\right\rangle_{A}=\beta \Delta E$, right after the ELA change. Here $\beta$ is the mass-balance gradient. For 

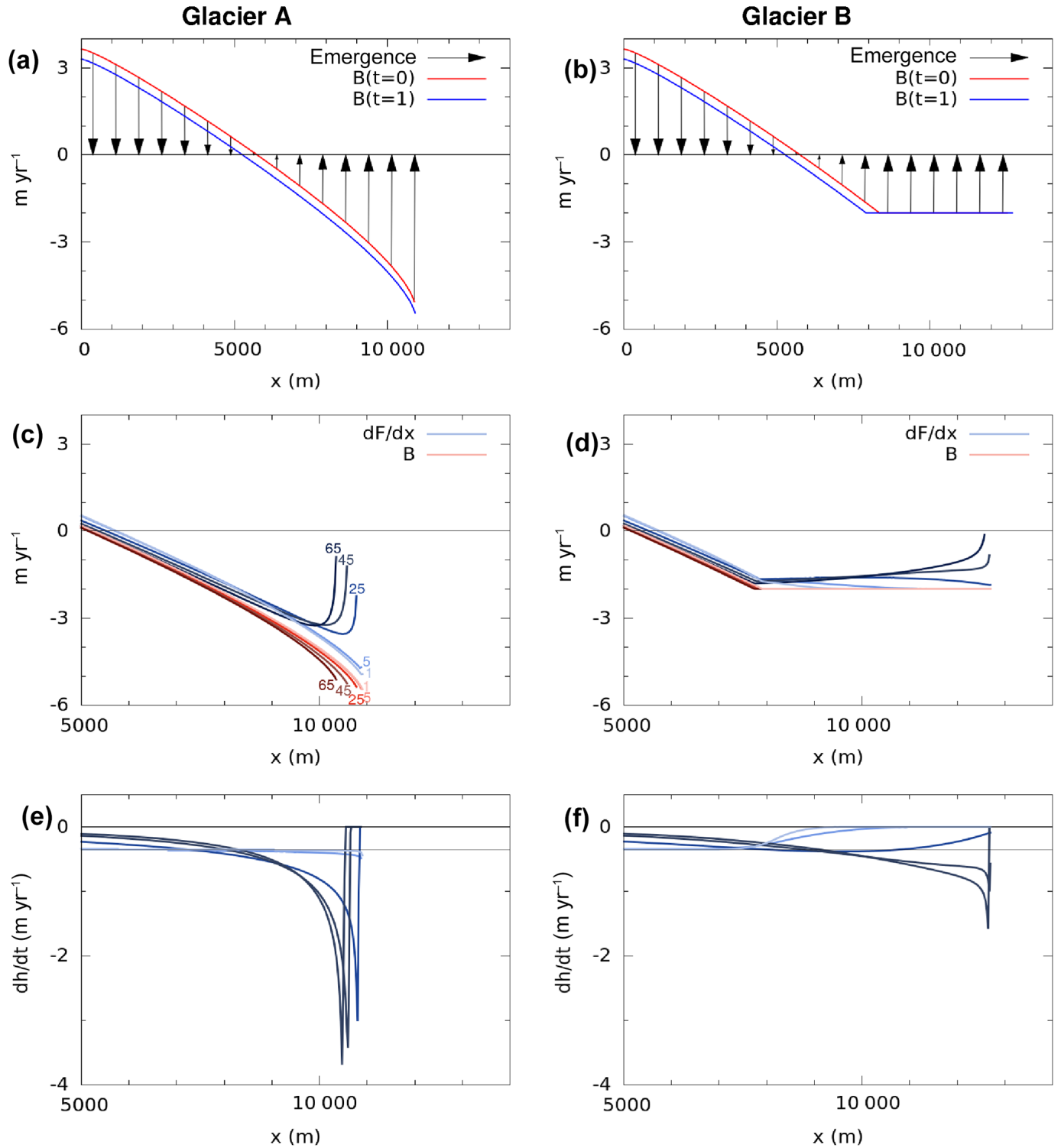

Figure 1. (a, b) The specific mass balance as a function of position for the initial steady-states of glaciers A and B (red lines). Black arrows denote the emergence velocities that balances the surface mass balance at $t=0$. The blue lines are the surface mass-balance profiles a year after a step change in ELA by $50 \mathrm{~m}$ (experiment 1). (c, d) The specific mass-balance (red lines) and flux-gradient (blue lines) profiles after $1,5,25,45$, and 65 years. In (c) the curves are labelled with the corresponding year. (e, f) The thinning rate profiles after 1, 5, 25, 45, and 65 years. Note the horizontal black thin lines at $\beta \Delta E=0.35 \mathrm{~m} \mathrm{yr}^{-1}$ (see text for details).

glacier B, a uniform thinning operates only on the debris-free upper part of the glacier and the lower part has not thinned at all (Fig. 1b). Thus, glacier B has a lower mean thinning rate to start with that is given by $\left\langle\frac{\mathrm{d} h}{\mathrm{~d} t}\right\rangle_{\mathrm{B}}=\left(1-f_{\mathrm{d}}\right) \beta \Delta E$, where $f_{\mathrm{d}}$ is the debris-covered fraction. Remarkably these expressions do not involve the lengths of the glaciers. Also, the initial lack of thinning on the debris-covered glacier is independent of the actual value of the melt rate under the thick debris layer (assumed to be $2 \mathrm{~m} \mathrm{yr}^{-1}$ here) and depends only on the general shape of the melt curve (Fig. 1b).
A more general mass-balance profile for a debris-covered glacier than the one considered above would involve a smaller or inverted mass-balance gradient in the debriscovered parts (Banerjee and Azam, 2016). Even then, the mean initial thinning rate on such a glacier would be less than that of a corresponding debris-free one. This delayed thinning of the debris-covered terminus is consistent with the formation of a slow-flowing stagnant tongue with very little retreat as observed on debris-covered glaciers in the HimalayaKarakoram (Scherler et al., 2011). This raises confidence in the minimal description of such glaciers that is being used 
here. In case of an inverted mass balance, a transient thickening of the lower ablation zone is observed, though this is likely to be an artefact of the assumed fixed shape of the mass-balance curve.

Thus, a debris-covered glacier starts with a lower value of mean thinning rate compared to a debris-free one (as $\left.\left\langle\frac{\mathrm{d} h}{\mathrm{~d} t}\right\rangle_{A}>\left\langle\frac{\mathrm{d} h}{\mathrm{~d} t}\right\rangle_{\mathrm{B}}\right)$. The ice fluxes then respond to the massbalance change and subsequent evolution of the flux-gradient profile, or equivalently that of the emergence velocity profile alters the distribution and magnitude of the thinning rate. Though the detailed spatial and temporal pattern of such changes are difficult to predict, at some later stage the thinning rate on glacier $\mathrm{B}$ is likely to become larger than that on glacier A. This is because (1) the debris-covered glacier B has a larger climate sensitivity (Banerjee and Shankar, 2013) compared to glacier A and thus loses more mass for the same change in the ELA; (2) on glacier B, the lower ablation zone responds to the perturbation with a delay. There must be an intermediate crossover period as well, where the thinning rates on both the glaciers have a similar magnitude within measurement errors.

\section{Numerical investigations}

To verify the above claims on the nature of the evolution of thinning rate on glaciers $\mathrm{A}$ and $\mathrm{B}$, we perform a set of numerical experiments with one-dimensional flowline models of glaciers A and B. The model glaciers have a bedrock slope of 0.1 and mass-balance gradient $\beta=0.007 \mathrm{yr}^{-1}$. See Banerjee and Shankar (2013) for further details of the flowline model used. Note that these glaciers are identical above the debriscovered region (Fig. 1a, b). The initial steady states are prepared by running the models with a fixed value of ELA for 500 (900) years for glacier A (B). The steady-state lengths of the simulated glaciers are in the range $6-14 \mathrm{~km}$. Subsequently, the following ELA perturbations are switched on at $t=0$.

\section{An instantaneous rise by $50 \mathrm{~m}$.}

2. A total rise of $50 \mathrm{~m}$ in steps of $5 \mathrm{~m}$ every 5 years.

3. A total rise of $30 \mathrm{~m}$ in steps of $1 \mathrm{~m}$ every 5 years.

In all three experiments the net warming is similar, but the rates and durations of the ELA perturbations are different $\left(1-\right.$ an instantaneous warming; 2 - a rate of $10 \mathrm{~m}$ decade $^{-1}$ for 50 years; 3 - a rate of $2 \mathrm{~m} \mathrm{decade}^{-1}$ for 150 years). In experiment 3, we restrict the total ELA rise to $30 \mathrm{~m}$ so as to limit the duration of the experiment to 150 years to facilitate comparison with the other two experiments.

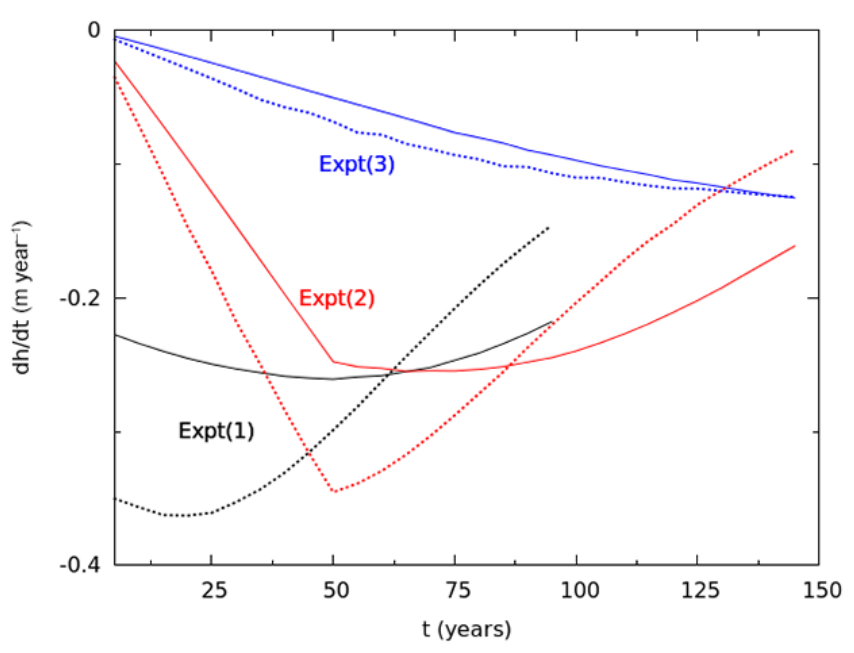

Figure 2. Evolution of thinning rates after ELA perturbations are applied to a model debris-covered glacier (solid line) and a debrisfree glacier (dotted line). The warming rate profiles for each of the experiments are described in Sect. 3.

\subsection{Results and discussions}

\subsubsection{Initial thinning rates}

Just as argued in Sect. 2, mean thinning rate profiles obtained after a year in experiment 1 show uniform thinning all over glacier A and in the upper part of glacier B (Fig. 1e, f). In contrast, the debris-covered parts of glacier B show no thinning. At this point, the flux gradient profile (same as the negative of emergence velocity), $\frac{\mathrm{d} F}{\mathrm{~d} x}$, has not changed significantly from the initial steady mass-balance profile $B(x)$ (Fig. 1c, d). Further, the initial thinning rates for glaciers $A$ and $\mathrm{B}$ in experiment 1 are quite accurately given by $\beta \Delta E$ $\left(0.35 \mathrm{~m} \mathrm{yr}^{-1}\right)$ and $\left(1-f_{\mathrm{d}}\right) \beta \Delta E\left(0.22 \mathrm{~m} \mathrm{yr}^{-1}\right)$. All these results are consistent with our arguments as outlined in Sect. 2. The thinning rate trends for finite warming rates follow a similar pattern. However, the difference between the thinning rates of glaciers $\mathrm{A}$ and $\mathrm{B}$ decreases for smaller warming rates (Fig. 2; experiments 2 and 3 ).

\subsubsection{Time evolution of the thinning rates}

A thinning of ice in the ablation zone takes place when the local melt rate overcomes the local emergence velocity. Data from experiment 1 show that the initial profile of the thinning rate gets modified at later times, largely due to a changing profile of $\frac{\mathrm{d} F}{\mathrm{~d} x}$ (Fig. 1e, f). After the initial rapid change, the competing term of mass-balance rate varies weakly with time due to a feedback from the changing ice thickness. Therefore, the evolution of the spatial distribution and the mean value of the thinning rate are mostly dynamically controlled by a changing emergence velocity profile. While this is in general true for both glaciers types, emergence velocity profile on the lower ablation zone of the debris-covered glacier shows 
a delayed response (Fig. 1f), which leads to a low glacieraveraged initial thinning rate for these glaciers.

Consistent with arguments given in Sect. 2, the mean thinning rate on glacier B has a lower magnitude initially. Subsequently the thinning rate matches and then overtakes that of glacier A (Fig. 2). This illustrates that, depending on the stage of response, a debris-covered glacier can have a smaller, larger or similar mean thinning rate compared to that of a corresponding debris-free glacier. As expected, similar trends are obtained in experiments with finite warming rates. However, at the limit of a very low rate of warming, the differences between the thinning rates on the two glaciers are small (Fig. 2; experiment 3). The crossover time seems to be controlled by the rate of warming.

While we have considered the glacier-wide thinning rate, the same conclusions are obtained if one compares only the lower part of the two glaciers as they are identical in their upper parts. The thinning rate, when measured on a regional scale, is an average over glaciers having a different size, shape, bedrock profile, and even a different history of warming. Clearly, in the light of the above discussion, this may lead to larger, smaller, or similar mean thinning rates in the debris-covered glaciers compared to the debris-free glaciers from the same region, in agreement with observations by Gardelle et al. (2013).

\section{Conclusions}

We provide very general arguments that debris-covered glaciers, while responding to a warming climate, can have smaller, larger or similar thinning rates compared to corresponding debris-free glaciers. The thinning of glaciers is controlled by a competition between a changing mass balance and the emergence velocity profile. A debris-covered glacier starts with a smaller glacier-averaged thinning rate, but overtakes that of a debris-free glacier at later stages of evolution. The initial difference in the corresponding thinning rates depend on the balance gradient and the debris-covered fraction. The changes in local melt rates control the thinning of glacial ice immediately after an instantaneous warming, whereas a stronger variation of the corresponding emergence velocity profile dictates the evolution of the thinning of ice at subsequent stages. Our arguments are validated against results from flowline model simulations of idealised glaciers.

Acknowledgement. This work is supported by DST-SERB grant no SB.DGH-71.2013 and DST-INSPIRE Faculty award (IFA-12EAS-04).

Edited by: G. Hilmar Gudmundsson

Reviewed by: three anonymous referees

\section{References}

Anderson, L. S. and Anderson, R. S.: Modeling debris-covered glaciers: response to steady debris deposition, The Cryosphere, 10, 1105-1124, doi:10.5194/tc-10-1105-2016, 2016.

Banerjee, A. and Azam, M. F.: Temperature reconstruction from glacier length fluctuations in the Himalaya, Ann. Glaciol., 57 (71), 189-198, 2016.

Banerjee, A. and Shankar, R.: On the response of Himalayan glaciers to climate change, J. Glaciol., 59, 480-490, 2013.

Benn, D. I., Bolch, T., Hands, K., Gulley, J., Luckman, A., Nicholson, L. I., Quincey, D., Thompson, S., Toumi, R., and Wiseman, S.: Response of debris-covered glaciers in the Mount Everest region to recent warming, and implications for outburst flood hazards, Earth-Sci. Rev., 114, 156-174, 2012.

Gardelle, J., Berthier, E., and Arnaud, Y.: Slight mass gain of Karakoram glaciers in the early twenty-first century, Nat. Geosci., 5, 322-325, 2012.

Gardelle, J., Berthier, E., Arnaud, Y., and Kääb, A.: Region-wide glacier mass balances over the Pamir-Karakoram-Himalaya during 1999-2011, The Cryosphere, 7, 1263-1286, doi:10.5194/tc7-1263-2013, 2013.

Juen, M., Mayer, C., Lambrecht, A., Han, H., and Liu, S.: Impact of varying debris cover thickness on ablation: a case study for Koxkar Glacier in the Tien Shan, The Cryosphere, 8, 377-386, doi:10.5194/tc-8-377-2014, 2014.

Kääb, A., Berthier, E., Nuth, C., Gardelle, J., and Arnaud, Y.: Contrasting patterns of early twenty-first-century glacier mass change in the Himalayas, Nature, 488, 495-498, 2012.

Mattson, L. E., Gardner, J. S., and Young, G. J.: Ablation on debris covered glaciers: an example from the Rakhiot Glacier, Punjab, Himalaya, IAHS Publ. 218 (Symposium at Kathmandu 1992 Snow and Glacier Hydrology), 289-296, 1993.

Miles, E. S., Pellicciotti, F., Willis, I. C., Steiner, J. F., Buri, P., and Arnold, N. S.: Refined energy-balance modelling of a supraglacial pond, Langtang Khola, Nepal, Ann. Glaciol., 57 (71), 29-40, 2016.

Naito, N., Nakawo, M., Kadota, T., and Raymond, C. F.: Numerical simulation of recent shrinkage of Khumbu Glacier, Nepal Himalayas. IAHS Publ. 264, Symposium at Seattle 2000 - DebrisCovered Glaciers, 245-254, 2000.

Nakawo, M. and Young, G. J.: Estimation of glacier ablation under a debris layer from surface temperature and meteorological variables, J. Glaciol., 28, 29-34, 1982.

Nuimura, T., Fujita, K., Yamaguchi, S., and Sharma, R. R.: Elevation changes of glaciers revealed by multitemporal digital elevation models calibrated by GPS survey in the Khumbu region, Nepal Himalaya, 1992-2008, J. Glaciol., 58, 648-656, 2012.

Reid, T. D. and Brock, B. W.: Assessing ice-cliff backwasting and its contribution to total ablation of debris-covered Miage glacier, Mont Blanc massif, Italy, J. Glaciol., 60, 3-13, 2014.

Rowan, A. V., Egholm, D. L., Quincey, D. J., and Glasser, N. F.: Modelling the feedbacks between mass balance, ice flow and debris transport to predict the response to climate change of debriscovered glaciers in the Himalaya, Earth Planet. Sci. Lett., 430, 427-438, 2015.

Sakai, A., Takeuchi, N., Fujita, K., and Nakawo, M.: Role of supraglacial ponds in the ablation process of a debris-covered glacier in the Nepal Himalayas, IAHS Publ. 265, 119-132, 2000. 
Scherler, D., Bookhagen, B., and Strecker, M. R.: Spatially variable response of Himalayan glaciers to climate change affected by debris cover, Nat. Geosci., 4, 156-159, doi:10.1038/ngeo1068, 2011.

Steiner, J. F., Pellicciotti, F., Buri, P., Miles, E. S., Immerzeel, W. W., and Reid, T. D.: Modelling ice-cliff backwasting on a debriscovered glacier in the Nepalese Himalaya, J. Glaciol., 61, 889907, 2015.

Vacco, D. A., Alley, R. B., and Pollard, D.: Glacial advance and stagnation caused by rock avalanches, Earth Planet. Sci. Lett., 294, 123-130, 2010.
Vincent, C., Wagnon, P., Shea, J. M., Immerzeel, W. W., Kraaijenbrink, P., Shrestha, D., Soruco, A., Arnaud, Y., Brun, F., Berthier, E., and Sherpa, S. F.: Reduced melt on debris-covered glaciers: investigations from Changri Nup Glacier, Nepal, The Cryosphere, 10, 1845-1858, doi:10.5194/tc-10-1845-2016, 2016. 